http://dx.doi.org/10.32929/2446-8355.2019v28n2p179-193

\title{
ATRIBUTOS FÍSICOS, MORFOLOGIA E COMPOSIÇÃO CENTESIMAL DO CÁRTAMO
}

Filipe Rodrigues Valeriano ${ }^{1}$, Marcela Carlota Nery ${ }^{2 *}$, Nisia Andrade Villela Dessimoni Pinto ${ }^{3}$, Mahany Graça Martins ${ }^{4}$, Andréa dos Santos de Oliveira ${ }^{5}$, Fernanda Carlota Nery ${ }^{6}$, Cíntia Maria Teixeira Fialho ${ }^{7}$

\footnotetext{
${ }^{1}$ Doutorando, Biotecnologia Vegetal e Bioprocessos, Universidade Federal do Rio de Janeiro Rio de Janeiro-RJ.

2 Docente, Agronomia, Universidade Federal dos Vales do Jequitinhonha e Mucuri, Diamantina-MG.* nery.marcela@ufvjm.edu.br

${ }^{3}$ Docente, Ciência e Tecnologia de Alimentos, Universidade Federal dos Vales do Jequitinhonha e Mucuri, Diamantina-MG.

${ }^{4}$ Mestranda, Produção Vegetal, Universidade Federal dos Vales do Jequitinhonha e Mucuri, Diamantina-MG.

${ }^{5}$ Docente, Agronomia, Universidade do Estado de Mato Grosso, Cáceres-MT.

${ }^{6}$ Docente, Engenharia de Biossistemas, Universidade Federal de São João del-Rei, São João del-Rei-MG.

${ }^{7}$ Docente. Agronomia, Universidade Tecnológica Federal do Paraná, Santa Helena-PR
}

Recebido: 07/02/2018; Aceito: 13/06/2019

RESUMO: O cártamo é apreciado pelo seu óleo rico em ácidos graxos poli-insaturados e monoinsaturados obtido de suas sementes. Dessa forma, para uma melhor compreensão das estruturas da semente e seus processos fisiológicos, objetivou-se com este trabalho estudar os grãos de cártamo, com caracterização morfológica, composição centesimal, atributos físicos e sanidade. Foi realizada a caracterização do lote e, posteriormente, a caracterização morfológica dos grãos, das plântulas e a composição centesimal dos grãos de cártamo. Além disso, realizou-se a determinação do número de sementes sem "casca", os estudos de análise de imagem. A composição centesimal se caracteriza pela presença de elevados teores de extrato etéreo, o que permitiu confirmar a espécie como oleaginosa. Pelo teste de sanidade observou-se maior incidência de fungos patogênicos, como Alternaria sp. e Fusarium sp. Conclui-se que o grão de cártamo é tetragonal, eurispérmico, e sendo classificado como bitegumentado, com a testa lisa. O embrião é facilmente observado quando hidratado, sendo aclorofilado de coloração branca e os cotilédones são carnosos, planos, longos e de contorno aproximadamente circular.

Palavras-chave: Carthamus tinctorius. Morfoanatomia. Biometria.

\section{PHYSICAL ATTRIBUTES, MORPHOLOGY AND CENTENAMENTAL COMPOSITION OF THE SAFFLOWER}

\begin{abstract}
Safflower is appreciated by oil rich in polyunsaturated and monounsaturated fatty acids obtained from its seeds. Thus, for a better understanding of the seed structures and their physiological processes, the objective of this work was to study the safflower grains, with morphological characterization, centesimal composition and sanity. The batch characterization was carried out and the morphological characterization of the grains and
\end{abstract}


seedlings and the centesimal composition of the safflower grains were carried out. In addition, the determination of the number of seeds without "bark", the studies of seed image analysis. The centesimal composition is characterized by the presence of high levels of ethereal extract, which allowed to confirm the species as oleaginous. The sanitary quality test showed a higher incidence of pathogenic fungi such as Alternaria sp. and Fusarium sp. It is concluded that the safflower grain is tetragonal, eurispermic, and being classified as bitegumentate, with a smooth front.The embryo is easily observed when hydrated, being white aclorophylate and the cotyledons are fleshy, flat, long and approximately circular in outline.

Key words: Carthamus tinctorius. Morfoanatomy. Biometry.

\section{INTRODUÇÃO}

O Carthamus tinctorius L., conhecido comumente como cártamo, é uma espécie de planta anual, do tipo herbácea, que compõe a família das Asteraceae. Possui vantagem devido a sua adaptabilidade a condições edafoclimaticas, como em regiões de solos com baixa fertilidade, clima diversificado e baixa taxa de umidade requerida. A soma desses fatores possibilita que está espécie seja considerada como potencial para o cultivo em ambientes como o semiárido (SANTOS; SILVA, 2015).

As sementes do cártamo possuem elevados teores de óleo (35 a 45\%) de ótima qualidade tanto para consumo humano como para uso industrial. $\mathrm{O}$ óleo de cártamo apresenta altos teores de ácido oleico (70-75\%) e linoleico (70-75\%), sendo as cultivares comerciais classificadas nesses dois grupos, conforme a percentagem desses ácidos graxos (HAMDAN et al., 2009). Além disso, atualmente o cártamo tem sido alvo de estudos devido ao seu potencial para produção de biocombustíveis, é e amplamente cultivado na Índia, Estados Unidos e Japão, entre outros (GALANT et al., 2015). No entanto, pesquisas estão sendo realizadas com o propósito de aumentar a produção e rendimento do seu óleo (EL-LATTIEF, 2012). Suas sementes também podem ser utilizadas para alimentação de pássaros e, as plantas na alimentação de ruminantes, cujo fornecimento poderá ser feito por meio de feno (DANIELI et al., 2011).

Muitos aspectos ainda são poucos explorados pela cultura, sendo necessário intensificar os estudos científicos sobre a espécie para que possa ser melhor aproveitada. Entre estes aspectos, os estudos da morfologia das sementes são importantes, pois contribuem para a propagação das espécies e identificação das espécies em campo. Com vista ao que foi exposto, o objetivo deste trabalho foi desenvolver os estudos referentes aos aspectos morfoanatômicos, vigor, composição centesimal e verificar os atributos físicos das sementes de cártamo.

\section{MATERIAL E MÉTODOS}

Os trabalhos foram realizados no Laboratório de Sementes do Departamento de Agronomia, no Laboratório de Biomassas do Cerrado do Departamento de Nutrição e no Laboratório de Anatomia Vegetal do Departamento de Ciências Biológicas da Universidade 
Federal dos Vales do Jequitinhonha e Mucuri - UFVJM, Diamantina, MG. Foram utilizados grãos de cártamo adquiridos da empresa Terra dos Pássaros, safra 2015.

O delineamento utilizado foi o inteiramente casualizado, com quatro repetições de 50 sementes.

Para a caracterização dos grãos foram realizadas as seguintes determinações e testes:

O grau de umidade das sementes foi obtido por meio do método da estufa, a $105^{\circ} \mathrm{C}$, por

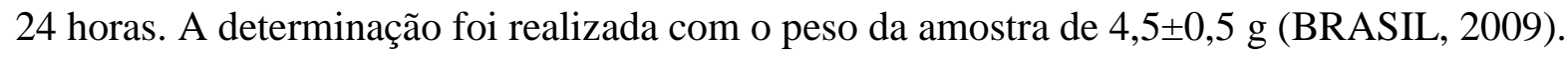

O teste de germinação foi realizado segundo os critérios estabelecidos pelas Regras de Análise de Sementes (BRASIL, 2009), no qual se utilizou rolo de papel germitest, à temperatura de $25^{\circ} \mathrm{C}$ com fotoperíodo de 12 horas. As avaliações foram realizadas ao $4^{\circ}$ dia (primeira contagem da germinação) e ao $14^{\circ}$ dia (contagem final). $\mathrm{O}$ índice de velocidade de germinação (IVG) foi obtido em conjunto com o teste de germinação, computando-se diariamente as sementes germinadas segundo Maguire (1962).

Para o teste de emergência de plântulas, as sementes foram semeadas em caixas plásticas contendo terra e areia na proporção 2:1, umedecida com água destilada. As caixas foram mantidas em sala de crescimento à temperatura de $25^{\circ} \mathrm{C}$ com fotoperíodo constante. As avaliações foram realizadas no $4^{\circ}$ dia (primeira contagem), sendo o teste encerrado após a porcentagem de emergência estabilizar a sua instalação (ocorreu aos $14^{\circ}$ dia), avaliando o número de plântulas normais emergidas. Quando se iniciou a emergência, foram realizadas avaliações diárias, computando-se o estande inicial ao $4^{\circ}$ dia e o número de plântulas emergidas, até a estabilização. Para o índice de velocidade de emergência (IVE) foram computados, diariamente, o número de plântulas emersas a partir do início da emergência, e o cálculo foi realizado conforme Maguire (1962).

A caracterização morfológica de plântulas foi realizada em conjunto com o teste de germinação. Na finalização do teste, foram selecionadas 10 plântulas normais para cada repetição e analisados o comprimento do hipocótilo, dos cotilédones e o comprimento da radícula. Em conjunto, realizou-se a determinação da massa fresca das plântulas com o auxílio de uma balança analítica. Para determinação do peso de mil sementes foram contadas oito repetições de 100 sementes de cada amostra, após o quê foi calculado o peso de cada repetição e determinados a variância e o desvio padrão (BRASIL, 2009).

Para a caracterização morfológica dos grãos foram observadas as estruturas e características visuais das sementes. Os grãos foram classificados quanto ao seu formato e foram calculadas suas dimensões (biometria) em milímetros por meio do paquímetro digital, obtendo os valores da média e desvio padrão.

As descrições dos aspectos morfológicos foram feitas segundo Beltrati (1995) e Barroso, et al. (1999).

Realizou-se o teste de sanidade em grãos de cártamo pelo método do papel filtro, com o uso de 2,4-D. Os grãos foram dispostos em gerbox sobre três folhas de papel filtro embebidas com ágar-água e 2,4-D a 1\%, e 0,5\% D.M.A, estando estes esterilizados. As sementes foram desinfestadas em álcool 70\% e hipoclorito de sódio 2,5\% (v/v) por 10 min e lavadas em água 
esterilizada. Realizadas as montagens do teste, os gerbox foram mantidos em B.O.D a $20^{\circ} \mathrm{C}$, com fotoperíodo de 12 horas, por 7 dias. Foi avaliada a presença e identificados os tipos de fungos nas sementes com auxílio de lupa e microscópio (BARNETT; HUNTER, 1986).

Para a composição centesimal, as sementes foram secas e trituradas em liquidificador, sendo as análises realizadas em triplicata. $\mathrm{O}$ grau de umidade foi obtido através do método da estufa, a $60^{\circ} \mathrm{C}$, por 24 horas. A determinação foi realizada com 3 repetições, com o peso da amostra de 5,0 g. Em conjunto com o grau de umidade foi determinado o teor de massa seca.

Para o extrato etéreo, a determinação foi feita com solvente orgânico (éter etílico) (AOAC, 1990). A determinação da proteína bruta ( $\mathrm{N}$ total) foi baseada na determinação de nitrogênio total, pelo método de micro-Kjeldahl (AOAC, 1990), aplicando-se o fator 6,25 para o cálculo do teor de proteína bruta. A partir deste método determinou-se a porcentagem de massa seca. Para fibra bruta, o material desengordurado foi digerido em ácido acético, ácido tricloracético e ácido nítrico e levado para estufa a $105 \pm 3^{\circ} \mathrm{C}$, por 24 horas. Por diferença entre o peso do conjunto e o peso do cadinho vazio foi expressa a quantidade de fibra bruta na amostra (VON DE KAMER; VAN GINKEL, 1952).

Para cinzas, foram pesadas aproximadamente 5,0 g da amostra em cadinho. Em seguida, estas foram carbonizadas e logo depois incineradas a $550^{\circ} \mathrm{C} \mathrm{em}$ forno mufla até obter cinzas claras. Após, foram retiradas e mantidas em dessecador até esfriar e foram realizadas as devidas pesagens.

O teor de carboidratos foi calculado pela diferença entre 100 e a soma das porcentagens do grau de umidade, cinzas, fibra, proteínas e lipídeos. O cálculo da energia foi feito a partir dos teores de proteínas, lipídios e carboidratos, levando em consideração os valores de conversão para carboidratos e proteína que equivalem a 4 kcal e lipídios 9 kcal. Para o pH foram pesadas $5 \mathrm{~g}$ e estas, diluídas em $50 \mathrm{~mL}$ de água destilada e agitadas. Após decantar o líquido sobrenadante para outro frasco foram realizadas as determinações.

Os sólidos solúveis totais foram determinados com auxílio do refratômetro manual. A acidez total titulável foi obtida por titulação, segundo a técnica estabelecida pelo Instituto Adolfo Lutz (1985). Os açúcares solúveis totais, redutores e não redutores foram extraídos pelo método de Lane-Enyon (AOAC, 1990) e determinados pela técnica de Somogy (1945), adaptada anteriormente por Nelson (1944). Os amidos foram determinados pelo método de Somogy segundo Nelson (1944).

A determinação do número de sementes sem "casca" foi realizado segundo Brasil (2009). Utilizou-se uma amostra de $90 \mathrm{~g}$ de grãos de cártamo; em seguida realizou a separação da amostra, contando-se as sementes sem "casca" para compor a porção "Semente Pura". O resultado é expresso em número de sementes sem "casca" ou com "casca" em relação ao peso da mostra de trabalho.

Para os estudos de análise de imagem de sementes foram utilizadas quatro repetições de 50 sementes para cada lote. Para a realização da captura da imagem, as sementes foram colocadas na bandeja de leitura. A captura das imagens foi realizada por uma câmera profissional de alta resolução contida dentro da câmara de captação do equipamento SAS ${ }^{\circledR}$ Sistema de Análise de Sementes, é um sistema computadorizado lançado pelo Tbit 
tecnologias e Sistemas, empresa incubada na Universidade Federal de Lavras (UFLA). Após a prévia captura das imagens das sementes pelo $\mathrm{SAS}^{\circledR}$, estas foram analisadas pelo próprio equipamento que aferiu o brilho, a cor, a intensidade e, a saturação da cor, a área, a área convexa, a circularidade e o perímetro.

Os dados foram submetidos à análise de variância e as médias comparadas entre si pelo teste de Scott-knott, a 5\% de probabilidade. As análises estatísticas foram realizadas com o auxílio do programa estatístico SISVAR ${ }^{\circledR}$ (FERREIRA, 2000).

\section{RESULTADOS E DISCUSSÃO}

Os grãos de cártamo apresentaram 6,13\% de grau de umidade (Tabela 1). Girardi et al. (2013a) encontraram grau de umidade entre 6,90 a 8,80\% para os lotes de sementes de cártamo. $\mathrm{O}$ grau de umidade recomendado para sementes oleaginosas deve estar entre 4 a 9\%, uma vez que o grau de umidade seja superior ao considerado seguro, pode incentivar o processo respiratório das sementes, a mobilização de reservas e liberação de energia, acelerando a deterioração.

Tabela 1. Resultados do grau de umidade - U; teste de germinação - G; primeira contagem da germinação - PC; emergência - E; estande inicial - EI; índice de velocidade de germinação - IVG; índice de velocidade de emergência - IVE e peso de mil sementes - PMS de grãos de cártamo para a caracterização do lote. Results of the degree of humidity - $U$; germination test - G; first germination count - PC; emergency - E; initial booth - EI; germination speed index - IVG; rate of emergence - IVE and weight of one thousand seeds PMS of safflower grains for the batch characterization.

\begin{tabular}{|c|c|c|c|c|c|c|c|c|}
\hline Lote & $\mathrm{U}$ & $G$ & $\mathrm{PC}$ & $\mathrm{E}$ & EI & IVG & IVE & PMS \\
\hline Cártamo & ------ & ------.. & $\%$ & -------- & --- & & & $\mathrm{g}$ \\
\hline Média & 6,13 & 64,00 & 61,00 & 88,00 & 84,00 & 35,89 & 18,40 & 37,20 \\
\hline$\overline{\overline{\mathrm{DP}}}$ & $\pm 0,49$ & $\pm \pm 6,73$ & $\bar{~} \pm 11,1$ & $\pm \pm 4,43$ & $\pm \pm 5,74$ & $\pm \pm 6,30$ & $\bar{~} \pm 1,29$ & 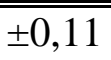 \\
\hline
\end{tabular}

A porcentagem média de germinação foi baixa, sendo em média 64\% (Tabela 1). Em trabalhos realizados por Freitas et al. (2018) com diferentes substratos a germinação do cártamo variou de $77,5 \%$ a $85,25 \%$. O que pode estar relacionada à qualidade sanitária deste lote, uma vez que patógenos associados às sementes podem comprometer consideravelmente o seu desempenho germinativo.

Durante o teste de germinação, foi observada presença de patógenos nos grãos de cártamo e o desenvolvimento de plântulas anormais infeccionadas (Figura 1). Outro fator importante a considerar são as finalidades da utilização de grãos comerciais, os quais são produzidos a fim de serem destinados para o consumo através da alimentação ou na utilização industrial; desta forma, são produzidos com qualidade levando em consideração as suas propriedades físicos-químicas o que justifica sua baixa qualidade fisiológica (PAES, 2006). O que também esclarece os baixos resultados para primeira contagem da germinação e índice de velocidade de germinação (Tabela 1). 


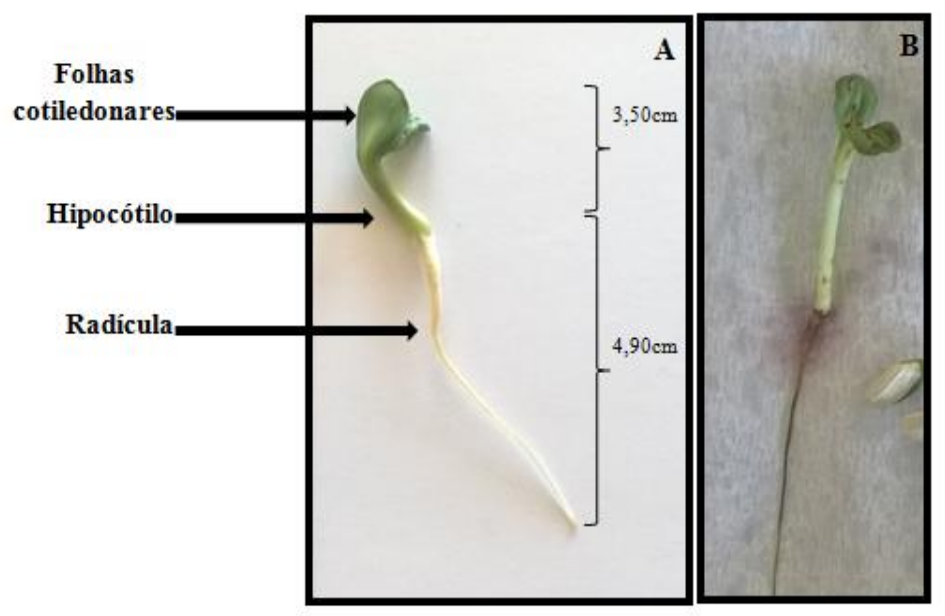

Figura 1. Plântula normal de cártamo (A) e plântula anormal infeccionadas com danos na radícula (B). Normal safflower seedlings (A) and abnormal seedlings infected with radicle damage $(B)$.

Observou-se que a porcentagem do teste emergência foi superior em relação ao teste de germinação (Tabela 1). Estes resultados podem ser explicados pela qualidade sanitária anteriormente citada no texto, que promoveu alto índice de plântulas anormais infeccionadas no teste de germinação, acima de $29 \%$. Vale ressaltar que, ao realizar o teste de emergência utilizando solo, as plântulas liberam o tegumento que pode estar infectado, diminuindo assim a deterioração e reduzindo as chances de plântulas anormais infectadas (GOULART, 1997). O estande inicial, IVE e emergência apresentaram elevadas médias (Tabela 1).

As plântulas normais de cártamo (Tabela 2), ao final do teste de germinação, apresentavam comprimento para o hipocótilo de 3,50 a 6,50 cm, radícula entre 1,30 a 8,00 $\mathrm{cm}$, os cotilédones mediram entre 0,70 a $3,10 \mathrm{~cm}$ e para a massa fresca observou-se acúmulo entre 2,25 a $2,59 \mathrm{~g}$.

Tabela 2. Resultados do comprimento do hipocótilo; cotilédones; raiz primária e matéria fresca; de grãos de cártamo obtidos a partir das plântulas normais do teste de germinação. Hypocotyl length results; cotyledons; primary root and fresh matter, of safflower grains obtained from normal seedlings of the germination test.

\begin{tabular}{|c|c|c|c|c|}
\hline \multicolumn{5}{|c|}{ Biometria das Plântulas de Cártamo } \\
\hline \multirow{2}{*}{ Parâmetro } & Hipocótilo & Radícula & Cotilédone & Massa Fresca \\
\hline & \multicolumn{3}{|c|}{ 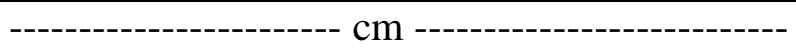 } & $\mathrm{g}$ \\
\hline Média & 4,73 & 3,86 & 1,49 & 2,46 \\
\hline Máximo & 6,50 & 8,00 & 3,10 & 2,59 \\
\hline Mínimo & 3,50 & $1,1,30$ & 0,70 & 2,25 \\
\hline Desvio Padrão & $\pm 0,73$ & $\pm 1,30$ & $\pm 0,50$ & $\pm 0,14$ \\
\hline
\end{tabular}

O peso de mil sementes para os grãos de cártamo obteve uma média de $37,25 \mathrm{~g}$, valor próximo ao encontrado por Abud et al. (2010), que foi em torno de 33,75 g. A partir do que foi reportado por Brasil (2009), os grãos deste lote podem ser classificados como pequenos, uma vez que o peso de mil sementes foi inferior a $200 \mathrm{~g}$. 
Pelo teste de sanidade (Tabela 3) de grãos de cártamo, foi possível constatar a maior incidência de gêneros de fungos considerados com grande potencial patogênico, como o Alternaria sp. e Fusarium sp. altos níveis de Alternaria sp., Aspergillus sp., e Fusarium sp., foram observados infectando sementes de cártamo colhidas em diferentes épocas (GIRARDI et al. 2013b). Para o gênero Fusarium, destaca-se o espécime Fusarium oxysporum f.sp. carthami que é responsável por ocasionar uma das doenças mais notórias a nível mundial para cultura, a murcha de Fusarium, considerada como um grande fator limitante para a produção (SINGH; KAPOOR, 2018).

Tabela 3. Porcentagem de incidência de fungos no lote de grãos de cártamo. Percentage of fungi incidence in the safflower grain plot.

\begin{tabular}{ccccc}
\hline \multicolumn{5}{c}{ Incidência (\%) } \\
\hline Lote & Alternaria $\mathrm{sp}$. & Aspergillus $\mathrm{sp}$. & Fusarium $\mathrm{sp}$. & Quetomio $\mathrm{sp}$. \\
\hline \hline Cártamo & 8 & 1 & 7 & 2 \\
\hline \hline
\end{tabular}

Observou-se, a partir da composição centesimal para os grãos de cártamo, que estes possuíam em torno de 5\% de grau de umidade e teores de massa seca em torno de $95 \%$ (Tabela 4). A massa seca representa a fração do material livre da umidade e onde estão contidos os nutrientes como carboidratos, proteínas e lipídeos, entre outros.

Tabela 4. Composição centesimal média em base seca de grãos de cártamo quanto ao grau de umidade - U; massa seca - MS; extrato etéreo - EE, proteína bruta - PB; fibra bruta - FB, cinzas - CZ, carboidratos - CARB e energia - ENERG. Mean centesimal composition in dry basis of safflower grains as to degree of moisture - U; dry mass - MS; ethereal extract - EE, crude protein - PB; crude fiber - FB, ash - CZ, carbohydrates - CARB and energy - ENERG.

\section{Composição Centesimal}

\begin{tabular}{|c|c|c|c|c|c|c|c|c|}
\hline Lote & $\bar{U}$ & MS & $\mathrm{EE}$ & $\mathrm{PB}$ & $\overline{F B}$ & $\mathrm{CZ}$ & $\overline{\text { CARB }}$ & ENERG \\
\hline & - & 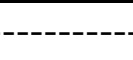 & - & - \% --- & $-\cdots$ & 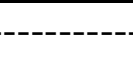 & $\begin{array}{l}--- \\
--1\end{array}$ & (kcal) \\
\hline Cártamo & 5,09 & 94,91 & 41,84 & 12,51 & 27,09 & 3,14 & 10,33 & 467,92 \\
\hline Desvio Padrão & $\pm 0,06$ & $\pm 0,06$ & $\pm 1,86$ & $\pm 0,56$ & $\pm 1,86$ & $\pm 0,32$ & & \\
\hline
\end{tabular}

O conteúdo lipídico (Extrato etéreo) é relativamente alto em grãos de cártamo e se encontra dentro do que é relatado na literatura, em torno de 41,84\% (Tabela 4). Abud et al. (2010) verificaram, em sementes de cártamo, teores de lipídeos em torno de 40\%, principal composto de reserva da semente, classificando-a como oleaginosa. Os lipídeos constituem uma forma importante de reservas para as sementes, geralmente na forma de trigiceróis, havendo ocorrência também na forma de glicolipídeos e fosfolipídeos (ABUD, 2010).

Quanto à proteína, o resultado obtido neste trabalho (Tabela 4) diferencia daqueles observado por Abud et al. (2010), que encontraram 36\% de proteína em sementes de cártamo. Brás et al. (2014), estudando a composição nutricional de torta de cártamo obtida após a prensagem dos grãos, concluiu que o conteúdo protéico é relativamente alto, alcançado uma porcentagem de $22,36 \%$. As sementes são consideradas importantes fontes de proteínas, armazenando as em sua forma concentrada. Esse fato é importante para um momento mais tardio, quando tais reservas serão utilizadas durante o processo de germinação e crescimento 
de plântulas, sendo uma fonte de aminoácidos crucial para o estabelecimento (TANWILSON; WILSON, 2012).

Em relação aos demais constituintes determinados, como as fibras (Tabela 4), observouse que estes apresentaram valores elevados por possuem um tegumento externo grosso, que envolve todo o grão, podendo ser este um dos aspectos para se explicar o alto teor de fibras encontrado. Os teores de fibra bruta encontrados em grãos de crambe variaram quando se determinava o teor para o grão inteiro $(14,3 \%)$, para grãos descascados $(3,6 \%)$ e para a casca $(22,1 \%)$, concluindo que a estrutura externa do grão acumulava grande quantidade de fibra.

O teor de cinzas encontrado para o cártamo neste estudo se encontra em concordância com o trabalho de Golkar et al. (2011), que reitera que esses valores podem variar entre 2 a $7 \%$. Um dos motivos de tal variação pode está associado com o teor de água da amostra. Segundo Vizzotto et al., (2012) a redução do teor de umidade pode promover o aumento de outros componentes, como matéria inorgânica.

O conteúdo de carboidratos encontrado foi de 10,33\% (Tabela 4). Os carboidratos, de forma geral, são compostos de dupla função (aldeído e álcool ou cetona e álcool) e têm como uma das principais funções a geração de energia. A partir do valor encontrado para energia, verificou-se relevância deste parâmetro, uma vez que em uma dieta humana, cuja necessidade diária para uma dieta é de 2000 calorias diárias (OLIVEIRA et al., 2006), o valor encontrado $(467,92 \mathrm{Kcal} / 100 \mathrm{~g})$ correspondeu a $23,4 \%$ da dieta, sendo considerado como um produto altamente calórico.

$\mathrm{O}$ valor de $\mathrm{pH}$ médio e acidez titulável para os extratos se encontram na Tabela 5. Ambos os parâmetros apresentam importância para conservação de alimentos agrícolas, sendo fatores limitantes para a presença microbiana e de interações químicas (LEMOS et al., 2015). Além disso, o referido autor ressalta a possibilidade de ocorrer a reação de Maillard, pelo fato do cártamo apresentar pH acima de 6,0. Deste modo, a produção de co-produtos obtidos a partir do cártamo, devem ser alvos de melhores processos de conversão a fim de se evitar alterações em seu meio.

Em relação aos valores de sólidos solúveis $\left(\right.$ Brix $\left.^{\circ}\right)$, que é um indicativo da quantidade de sacarose presente, não foram encontrados valores mínimos pré-estabelecidos para o cártamo. Entretanto, é sabido que esse parâmetro pode influenciar nas condições de armazenagem e na nutrição, sendo necessária a realização de mais estudos para melhores compreensões. Em alguns extratos de oleaginosas como o do amendoim, valores de Brix ${ }^{\circ}$ foram relatados variando entre $4,66^{\circ}$ a $9,83^{\circ}$ (OLIVEIRA et al., 2014)

Observa-se que o cártamo apresentou teores de açúcares, aproximadamente 0,33\% de açúcares totais, 0,24\% de açúcares não redutores e 0,09\% de açúcares redutores (Tabela 5). Teores de açúcares redutores (glicose e frutose) são quase inexpressíveis, visto que, em sementes maduras, eles são virtualmente ausentes, ocorrendo mais abundância de açúcares solúveis como a sacarose (CASTRO et al. 2004). A sacarose (açúcares não redutores) é muito utilizada para a obtenção de triglicerídeos e proteínas (BEWLEY; BLACK, 1994). 
Com relação ao teor de amido, foram observados valores, em média, de 2,07\% (Tabela 5). As sementes oleaginosas em desenvolvimento acumulam amido em seus constituintes (tecidos), em seguida serão mobilizados para que ocorra a síntese de triglicerídeos (BEWLEY; BLACK, 1994).

Tabela 5. Composição centesimal média em base seca de grãos de cártamo quanto ao potencial hidrogeniônico - $\mathrm{pH}$; sólidos solúveis totais; acidez total titulável; açúcares totais; açúcares não redutores; açúcares redutores e amido. Average dry matter composition of safflower grains in terms of hydrogen-pH potential; total soluble solids; titratable total acidity; total sugars; non-reducing sugars; reducing sugar and starch.

\begin{tabular}{|c|c|c|c|c|c|c|c|}
\hline \multicolumn{8}{|c|}{ Composição Centesimal } \\
\hline \multirow[t]{2}{*}{ Lote } & \multirow[t]{2}{*}{$\mathrm{PH}$} & $\begin{array}{c}\text { Sólidos } \\
\text { solúveis totais }\end{array}$ & $\begin{array}{c}\text { Acidez total } \\
\text { titulável }\end{array}$ & $\begin{array}{c}\text { Açúcares } \\
\text { totais }\end{array}$ & $\begin{array}{c}\text { Açúcares não } \\
\text { redutores }\end{array}$ & $\begin{array}{l}\text { Açúcares } \\
\text { redutores }\end{array}$ & Amido \\
\hline & & ( $\left.{ }^{\circ} \mathrm{Brix}\right)$ & $(\mathrm{g} / 100 \mathrm{~mL})$ & ----- & ---- $\%$ & ---------. & ------ \\
\hline Cártamo & 6,03 & 5,86 & 0,1 & 0,33 & 0,24 & 0,09 & 2,07 \\
\hline $\begin{array}{l}\text { Desvio } \\
\text { Padrão }\end{array}$ & $\pm 0,08$ & $\pm 0,64$ & $\pm 0,01$ & $\pm 0,13$ & $\pm 0,12$ & $\pm 0,03$ & $\pm 1,65$ \\
\hline
\end{tabular}

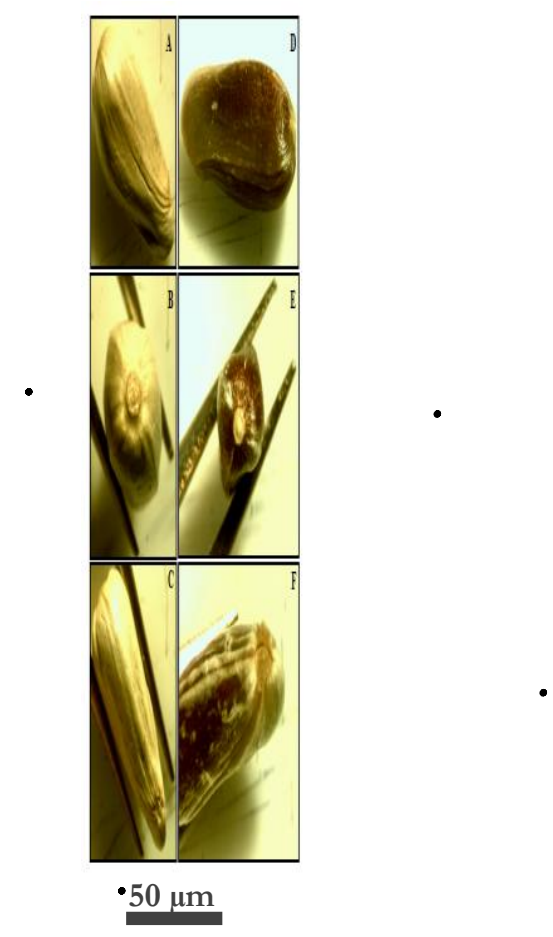

Figura 2. Aspectos externos dos grãos de cártamo secos (A) e hidratados (D). Base arredonda com a vista frontal do hilo em grãos secos (seta preenchida) (B) e hidratados (seta sem preenchimento) (E). Ápice achatado evidenciando a micrópila em grãos secos (seta preenchida) (C) e hidratados (seta sem preenchimento) (F). External aspects of dried safflower grains $(A)$ and hydrated $(D)$ grains. Base rounds with the front view of dry grain (filled arrow) $(B)$ and hydrated (unfilled) arrow $(E)$. Flattened apex showing the micropyle in dry grains (filled arrow) $(C)$ and hydrated (arrow without filling) $(F)$. 
A partir das características morfológicas, o grão de cártamo é tetragonal, sem pelos e pode ser classificado como eurispérmico devido ao seu formato irregular, apresentando um ápice achatado e base arredondada (BARROSO, et al. 1999; BELTRATI, 1995). A sua coloração é variável, conforme o estado de hidratação em que as sementes se encontram, apresentando coloração branca amarelada a acinzentada quando secas e marrom quando estão hidratadas (Figura 2A e 2D).

O hilo e a micrópila são bastante visíveis, estando sempre voltados para a mesma borda, fato este evidenciado por Abud et al. (2010). Ambas as estruturas encontram-se em regiões opostas, sendo o hilo localizado na região basal e apresentando o formato arredondado de coloração acinzentada (Figura 2B e 2E), ao passo que a micrópila apresenta um tamanho menor, estando discreta, com o formato circular e situa-se na região apical da semente (Figura $2 \mathrm{C}$ e $2 \mathrm{~F})$.

Na caracterização biométrica de grãos de cártamo (Tabela 6), verificou-se que os dados se encontram em consonância com os da literatura. Abud et al. (2010) verificaram dimensões aproximadas daquelas encontradas para cártamo, observando dimensões entre 5,56 e 7,78 mm de comprimento, de 3,59 a 4,91 $\mathrm{mm}$ de largura e de 2,78 a 3,98 $\mathrm{mm}$ de espessura.

Tabela 6. Resultados da biometria de grão de cártamo quando ao comprimento, largura e espessura. Results of safflower grain biometrics when length, width and thickness.

\begin{tabular}{cccc}
\hline & \multicolumn{4}{c}{ Biometria } \\
\hline \multirow{2}{*}{ Parâmetro } & Comprimento & Largura & Espessura \\
\cline { 2 - 4 } & $-\cdots, 18$ & 3,61 & 3,18 \\
\hline Média & 8,85 & 4,31 & 3,82 \\
\hline Máximo & 6,69 & 3,15 & 2,54 \\
\hline \hline Mínimo & $\pm 0,40$ & $\pm 0,28$ & $\pm 0,24$ \\
\hline \hline Desvio Padrão & &
\end{tabular}

Foi verificada, no lote de cártamo, a presença de grãos com casca e sem casca (Figura 3), para isso procedeu-se ao teste de número de sementes sem "casca" e número de sementes com "casca". A partir da análise, foi verificado que o lote apresentou em torno de 5,85\% grãos sem casca. Souza et al. (2007) reporta que, em sementes de arroz, a retirada de casca se deve à má regulagem do cilindro da colheitadeira no momento da colheita e, posteriormente, na passagem pelo equipamento de secagem e nos transportadores. Além disso, amostras descascadas tendem a apresentar menores valores em sua composição de nutrientes, apresentando menores valores de proteínas, fibras, cinzas, extrato etéreo, entre outros componentes, o que afeta no rendimento e direcionamento dentro da indústria (MAYER, 2007). 

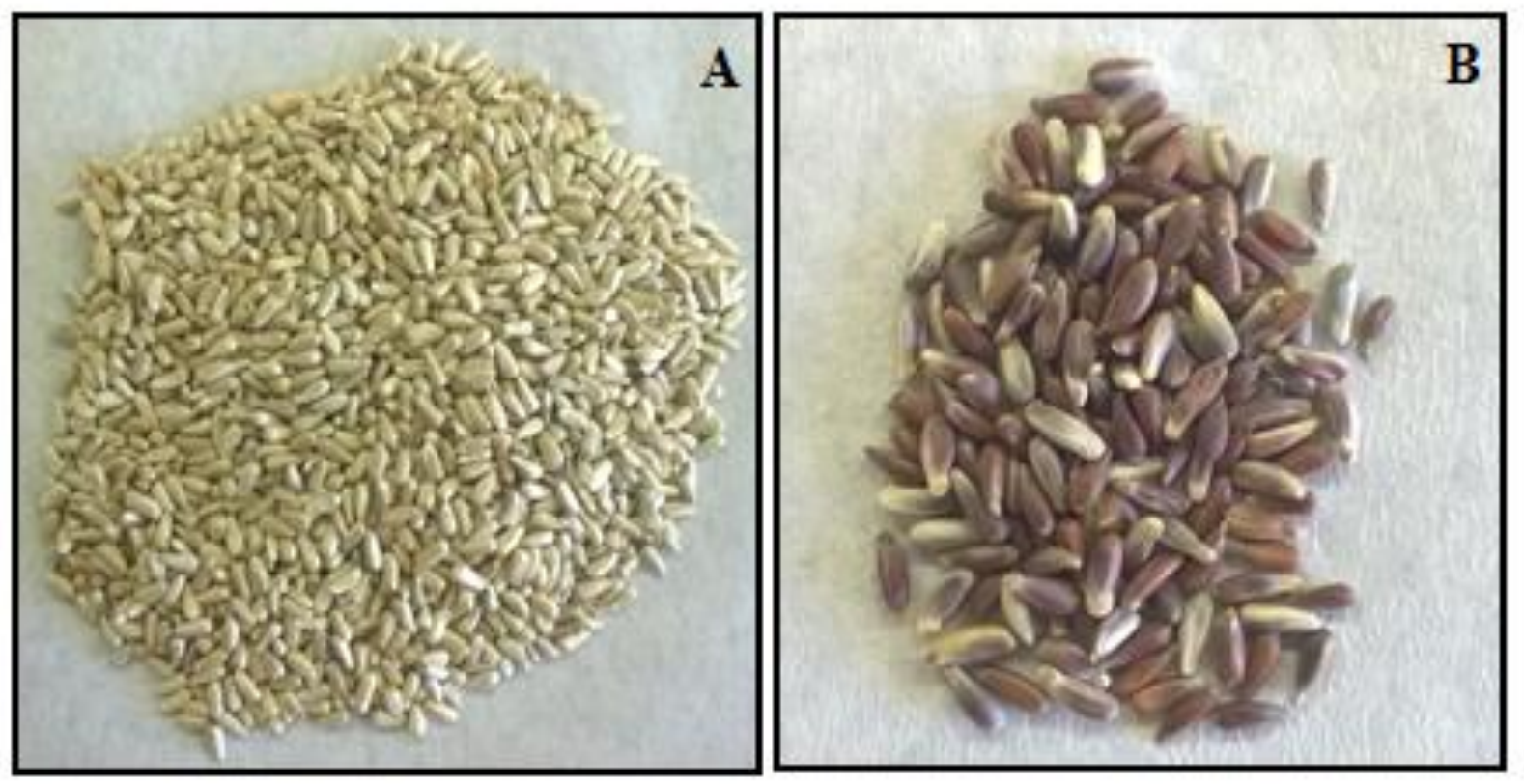

Figura 3. Amostra do teste do número de grãos de cártamo com casca (A) e sem casca (B). Sample of the test of the number of safflower grains with bark (A) and without bark (B).

$\mathrm{Na}$ Tabela 7, podem ser observadas as variáveis analisadas pelo Sistema de Análise de Sementes $\left(\mathrm{SAS}^{\circledR}\right.$ ), com suas respectivas médias e desvios padrão. Para o brilho do tegumento, observou-se uma média de 0,32 . O conhecimento sobre o brilho do tegumento se torna importante, visto que fornece informações para complementar a caracterização de cultivares da espécie em estudo. Em grãos de feijão, por exemplo, são observadas variações quanto o brilho, sendo classificadas quanto ao grau de intensidade (brilhante, médio e opaco). Além disso, o brilho do tegumento é uma característica avaliada na seleção e no lançamento de cultivares e apresenta importantes implicações para a produção, armazenamento e consumo (KONZEN; TSAI, 2014). Além destas informações, o parâmetro brilho, é de grande importância, uma vez que autores tem relacionado que o brilho do tegumento pode está relacionado como a resistência a fatores bióticos e abióticos (KONZEN; TSAI, 2014).

Tabela 7. Variáveis obtidas pela análise de imagem em grãos cártamo, como Brilho - BR; amarelo - AM; laranja - LJ; preto - PR; intensidade - IT; saturação - ST; área - AR; circularidade - CR e perímetro - PR. Variáveis obtidas pela análise de imagem em grãos cártamo, como Brilho - BR; amarelo - AM; laranja - LJ; preto - PR; intensidade - IT; saturação-ST; área - AR; circularidade - CR e perímetro - PR.

\begin{tabular}{cccccccccc}
\hline & \multicolumn{10}{c}{ Parâmetros } \\
\hline Lote & BR & AM & LJ & PR & IT & ST & AR & CR & PR \\
\hline Cártamo & 0,32 & 0,73 & 0,02 & 0,23 & 0,27 & 0,42 & 0,24 & 0,46 & 2,12 \\
\hline \hline
\end{tabular}

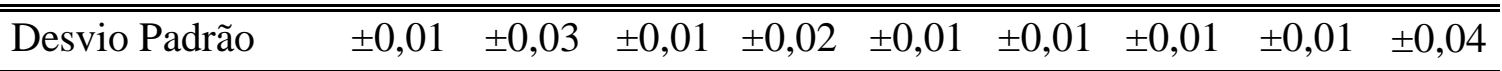

Observando valores médios de 0,73 para cor amarelo, 0,02 para a cor laranja e 0,23 para o preto. $\mathrm{Na}$ análise de sementes, variações como a coloração do tegumento apresentam importância, sendo considerada um dos descritores morfológicos usados quando se submete uma cultivar à proteção. Outro parâmetro importante reportado na literatura é a correlação entre a qualidade fisiológica das sementes e a coloração do tegumento (SANTOS et al, 2007). 
Para os parâmetros intensidade e saturação da cor exibida em grãos de cártamo, verificaram-se valores médios de 0,27 e 0,42. Estudos com a intensidade da cor têm sido importantes para compreender a presença de certos compostos em grãos de algumas culturas, como em grãos de milho, relacionando a intensidade de cor dos grãos com o perfil de carotenos pró-vitamina A (RIOS et al. 2007). Foi verificado que a área do grão obteve valores de 0,24 e a circularidade, de 0,46 . A circularidade é considerada um dos principais parâmetros a serem definidos para o dimensionamento do tamanho da malha das peneiras em equipamentos destinados a separação e classificação de grãos e sementes (SILVA; CORRÊA, 2008). O valor médio para o grão em relação ao seu perímetro foi de 2,12 .

\section{CONCLUSÃO}

A composição centesimal se caracteriza pela presença de elevados teores de extrato etéreo, o que permitiu confirmar a espécie como oleaginosa. Verificou-se que os grãos de cártamo são ricos em fibras, associando o maior acúmulo devido à presença de uma casca externa. Os grãos de cártamo apresentam-se como pequenos, tetragonais, eurispérmicos e com o ápice achatado, bitegumentado, com a testa lisa.

Pelo teste de sanidade observou-se maior incidência de fungos patogênicos, como Alternaria sp. e Fusarium sp. O embrião é facilmente observado quando hidratado, sendo aclorofilado de coloração branca e os cotilédones são carnosos, planos, longos e de contorno aproximadamente circular.

\section{REFERÊNCIAS BIBLIOGRÁFICAS}

ABUD, H. F.; GONÇALVES, N. R.; REIS, R. G. E.; GALÃO, M. I.; INNECCO, R. Morfologia de Sementes e Plântulas de Cártamos. Revista Ciência Agronômica, FortalezaCE, v. 41, n. 2, p.259-265, 2010.

ASSOCIATION OF OFFICIAL ANALYTICAL CHEMISTS - AOAC. Official methods of analysis of the association analytical chemists.12.ed. Washington: AOAC, 1990. 1140 p.

BARROSO, G. M.; MORIM, M. P.; PEIXOTO, A. L.; ICHASO, C. L.F. Frutos e sementes: morfologia aplicada à sistemática de dicotiledôneas. Viçosa: UFV, 1999. 443 p.

BARNETT, H. L.; HUNTER, B. B. Illustrated genera of fungi imperfect. 2. ed. New York: MacMilan, 1986. 218 p.

BELTRATI, C. M. Morfologia e anatomia de sementes. In: CURSO DE POSGRADUACAO EM CIENCIAS BIOLOGICAS, AREA DE BIOLOGIA VEGETAL. Apostila. Rio Claro: UNESP - Departamento de Botanica / Instituto de Biociencias, 1995. 98 p.

BEWLEY, J. D.; BLACK, M. Seeds: physiology of development and germination, New York: Plenum Press, 1994. 445 p. 
BRÁS, P; POSSENTI, R. A; BUENO, M. S; CANOVA, E. B; SCHAMMAS, E. A. Avaliação nutricional de coprodutos da extração de óleos vegetais em dieta de ovinos. Boletim de Indústria Animal, Nova Odessa, v. 71, n. 2, p.160-175, 2014.

BRASIL. Ministério da Agricultura, Pecuária e Abastecimento. Secretaria de Defesa Agropecuária. Regras para análise de sementes. Brasília, DF: MAPA/ACS, 2009. 365 p.

CASTRO, H. G.; OLIVEIRA, L. O.; BARBOSA, L. C. A.; FERREIRA, F. A.; SILVA, D. J. H.; MOSQUIM, P. R.; NASCIMENTO, E. A. Teor e composição do óleo essencial de cinco acessos de mentrasto. Química Nova, São Paulo, v. 27, n. 1, p.55-57, 2004.

DANIELI, P. P.; PRIMI, R.; RONCHI, B.; RUGGERI R.; ROSSINI, F.; PUGLIA, S.; CERETI, C. F. The potential role of spineless safflower (Carthamustinctorius L.var. inermes) as fodder crop in central Italy. Italian Journal of Agronomy, Pavia, v. 6, n. 1, p.19-22, 2011.

EL-LATTIEF, E. A. Evaluation of 25 safflower genotypes for seed and oil yields under arid environment in upper Egypt. Asian Journal of Crop Science, Dubai, v. 4, n. 2, p.72-79, 2012.

FERREIRA, D. F. SISVAR - Sistema de análise de variância para dados balanceados. Lavras: UFLA, 2000. (SISVAR 4.1 Pacote computacional)

FREITAS, R. B; FACHI, L. R.; ALBUQUERQUE, A. N. Substratos para o teste de germinação de sementes de cártamo (Carthamus tinctorius L.). Scientific Electronic Archives, Sinop, v. 11, n. 3, p.28-31, 2018.

INSTITUTO ADOLFO LUTZ. Normas Analíticas do Instituto Adolfo Lutz: Métodos químicos e físicos para análise de alimentos. 3 ed. São Paulo: IMESP, 1985. 1000 p.

GAlANT, N. B.; SANTOS, R. F.; SILVA, M. A. Melhoramento de cártamo. Acta Iguazu, Cascavel, v. 4, n. 1, p.14-25, 2015.

GIRARDI, L. B; LAZAROTTO, M.; DURIGON, M. R.; PEDROSO, D. C.; MULLER, J.; MUNIZ, M. F. B. Envelhecimento acelerado em sementes de cártamo. Revista da Faculdade de Zootecnia, Veterinária e Agronomia, Porto Alegre, v. 19, n. 1, p.43-54. $2013 \mathrm{a}$.

GIRARDI. L. B.; BELlÉ, R. A.; LAZAROTTO, M.; MICHELON, S.; GIRARDI, B. A. Qualidade de sementes de cártamo colhidas em diferentes períodos de maturação. Revista Acadêmica: Ciências Agrárias e Ambientais, Curitiba, v. 11, n. 1, p.S67-S73, 2013b.

GOLKAR, P., ARZANI, A., REZAEI, A. M. Genetic Analysis of Oil Content and Fatty Acid Composition in Safflower (Carthamus tinctorius L.). Journal of the American Oil Chemists' Society, Boulder, v. 88, n. 7, p.975-982, 2011.

GOUlART, A. C. P. Fungos em Sementes de soja: Detecção e importância. Dourados: Embrapa, 1997. 51 p.

HAMDAN Y.; PÉREZ-VICH, B.; VELASCO L.; FERNÁNDEZ-MARTÍNEZ, J. M. Inheritance of high oleic acid content in safflower. Euphytica, Holanda, v. 168, n. 1, p.61-69, 2009. 
INSTITUTO ADOLFO LUTZ. Normas analíticas: métodos químicos e físicos para análises de alimentos. 3. ed. São Paulo, 1985. 533 p.

KONZEN, E. R.; TSAI, S. M. Seed Coat Shininess in Phaseolus vulgaris: Rescuing a Neglected Trait by Its Screening on Commercial Lines and Landraces. Journal of Agricultural Science, Ontário, v. 6, n. 8, p.113-130, 2014.

LEMOS, D. M.; QUEIROZ, R. M. F.; FIGUEIRÊDO, A. J. M. Caracterização físicoquímica de sementes de noni. Revista GEINTEC, Aracaju, v. 5, n. 3, p.2308-2315, 2015.

MAGUIRE, J.D. Speed of germination-aid in selection and evaluation for seedling emergence and vigour. Crop Science, Madison, v. 2, n. 1, p.176-177, 1962.

MAYER, E. T.; FUKE, G.; NORNBERG, J. L.; MINELLA, E. Caracterização nutricional de grãos integrais e descascados de cultivares de cevada. Pesquisa Agropecuária Brasileira, Brasilia, v. 42, n. 11, p.1635-1640, 2007.

NELSON, N. A. Photometric adaptation of somogy method for the determination of glucose. Journal of Biological Chemistry, Rockville, v. 153, n. 1, p.375-384, 1944.

OLIVEIRA, M. C. L.; BENEDET, H. D.; PRUDÊNCIA, E. S. Caracterização química e avaliação sensorial de bebida hidroeletrolítica fermentada obtida a partir de permeado de leite tipo C. Revista Tecnologia, Fortaleza, v. 27, n. 1, p.50-57, 2006.

OLIVEIRA, T. K. B.; ALMEIDA, F. A. C.; CASTRO, D. S.; NUNES, J. S.; RAMOS, K. R. L. P. Análise físico-química do extrato aquoso do amendoim. Revista Verde, Pombal, v. 9, n. 2, p.121-124, 2014.

PAES, M. C. D. Aspectos físicos, químicos e tecnológicos do grão de milho. Sete Lagoas: Embrapa Milho e Sorgo, 2006. 6 p.

RIOS, S. A.; CARDOSO, W. S.; PAES, M. C. D.; BORÉM, A.; GUIMARAES, P. E. O.; SCHAFFERT, R. E.; TEIXEIRA, F. F.; GOMES, A. F. Influência da cor no perfil de carotenoides de grãos de milho para geração de cultivares biofortificados. In: CONGRESSO BRASILEIRO DE MELHORAMENTO DE PLANTAS: Melhoramento de plantas e agronegócio, 4, 2007, São Lourenço. Anais [....] Lavras: UFLA: SBMP, 2007. p. 1-3.

SANTOS, R. F.; SILVA, M. A. Carthamus tinctorius L.: Uma alternativa de cultivo para o Brasil. Acta Iguazu, Cascavel, v. 4, n. 1, p.26-35, 2015.

SANTOS, E. L.; POLA, J. N.; BARROS, A. S. R.; PRETE, C. E. C. Qualidade fisiológica e composição química das sementes de soja com variação na cor do tegumento. Revista brasileira de sementes, Londrina, v. 29, n. 1, p.20-26, 2007.

SILVA, J. S; CORRÊA, P. Estrutura, composição e propriedade dos grãos. In: SILVA, J. S. Secagem e armazenagem de produtos agrícolas. 2. ed. Viçosa: Aprenda Fácil Editora, 2008. cap. 2, p. 21-37.

SINGH, N.; KAPOOR, R. Quick and accurate detection of Fusarium oxysporum f. sp. carthami in host tissue and soil using conventional and real-time PCR assay. World Journal of Microbiology and Biotechnology, Heidelberg, v. 34, n. 175, p.1-12, 2018. 
SOMOGY, M. A. New regent for the determination of sugars. Journal of Biological Chemistry, Rockville, v. 160, n. 1, p.601-668, 1945.

SOUZA, L. C. D.; YAMASHITA, M. A. C. C. Qualidade de sementes de arroz utilizadas no norte de Mato Grosso. Revista Brasileira de Sementes, Londrina, v. 29, n. 2, p.223-228, 2007.

TAN-WILSON, A. L.; WILSON, K. A. Mobilization of seed protein reserves. Physiologia Plantarum, Sweden, v. 145, n. 1, p.140-153, 2011.

VIZZOTTO, T.; FELTES, M. M. C.; ROSA, A. D.; CARPINELli, N. A.; SCHUH, J.; GONÇALVES, L.; DORS, G. Determinação de umidade e cinzas em diversas matrizes Alimentares. In: II Mostra de Iniciação Científica, 2, 2012, Concórdia. Anais [...] IFC: Campus Concórdia, 2012. p. 1-5.

VON de KAMER, S. B.; VAN GINKEL, L. Rapid determination of crude fiber in cereals. Cereal Chemistry, Saint Paul, v. 19, n. 4, p.239-251, 1952. 